
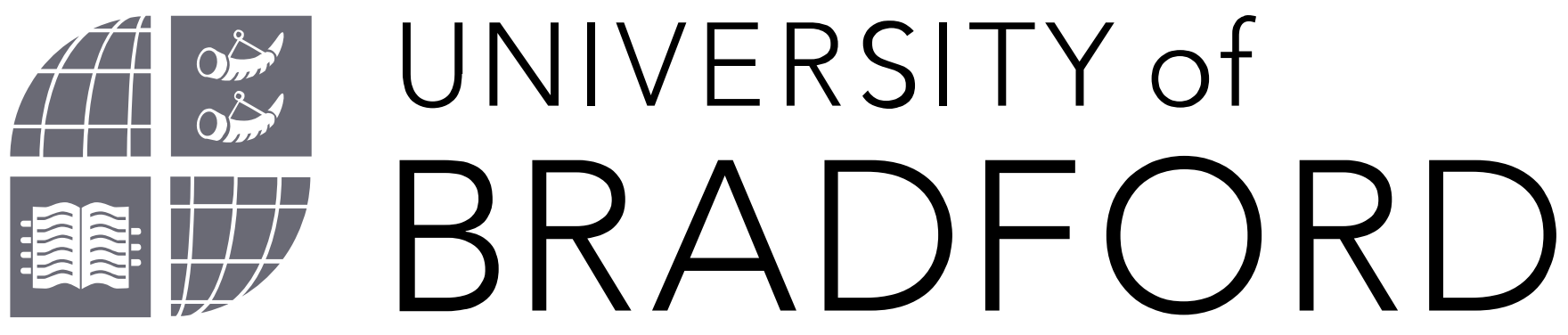

\title{
Attitudes, beliefs and impulsivity in online gambling addiction
}

\begin{tabular}{|c|c|}
\hline Item Type & Article \\
\hline Authors & Trivedi, Rohitkumar; Teichert, T. \\
\hline Citation & $\begin{array}{l}\text { Trivedi R and Teichert T (2018) Attitudes, beliefs and impulsivity in } \\
\text { online gambling addiction. International Gambling Studies. 18(2): } \\
\text { 327-342. }\end{array}$ \\
\hline Rights & $\begin{array}{l}\text { (c) } 2018 \text { Taylor \& Francis. This is an Author's Original Manuscript } \\
\text { of an article published by Taylor \& Francis in International } \\
\text { Gambling Studies on 09/05/2018 available online at https:// } \\
\text { doi.org/10.1080/14459795.2018.1466188. }\end{array}$ \\
\hline Download date & 27/07/2018 10:52:23 \\
\hline Link to Item & http://hdl.handle.net/10454/15640 \\
\hline
\end{tabular}




\section{The University of Bradford Institutional Repository}

http://bradscholars.brad.ac.uk

This work is made available online in accordance with publisher policies. Please refer to the repository record for this item and our Policy Document available from the repository home page for further information.

To see the final version of this work please visit the publisher's website. Access to the published online version may require a subscription.

Link to publisher version: https://doi.org/

Citation: Trivedi R and Teichert T (2018) Attitudes, beliefs and impulsivity in online gambling addiction. International Gambling Studies. Accepted for publication.

Copyright statement: (c) 2018 Taylor \& Francis. This is an Author's Original Manuscript of an article published by Taylor \& Francis in [JOURNAL TITLE] on [date of publication] available online at $\mathrm{xxxx}$. 
Trivedi, R., \& Teichert, T.

Delay discounting as a moderator of the attitude-addiction relation in online gambling. International Gambling Studies.

\title{
Attitudes, beliefs and impulsivity in online gambling addiction
}

\begin{abstract}
Gambling research often refers to attitude and belief measurements to distinguish between problem and non-problem gamblers. Past studies also indicated that problem gamblers have a tendency to steeply discount rewards. We join both research streams and investigate the relationships between attitudes and beliefs on gambling addiction with the moderating effects of delay discounting using a novel methodological approach of double-hurdle model. We hereby differentiate the five subdimensions of the Gambling Attitude and Belief Scale (GABS): emotions, chasing, luck, attitudes and strategies. Findings show that emotional predispositions and chasing tendencies are positively related to the severity of online gambling addiction, independent of gamblers' impulsivity. In contrast hereto, gambling attitudes act as inhibitor for gamblers willing to wait for some time to receive higher reward. Findings show that money-related impulsiveness influences the relationship between subdimensions of GABS and gambling addiction: Gambling attitudes and beliefs do not necessarily harm online gamblers but that their positive or negative relationship to addiction depends on online gamblers' impulsivity.
\end{abstract}

Keywords: Gambling attitude; Gambling beliefs; Addiction; Double-hurdle model; Online gambling; Impulsivity; Delay discounting

\section{Introduction}


Cognitive-behavior therapists focus on gambling-related attitudes and beliefs because of their significant contribution to addiction (Toneatto \& Millar, 2004). The Gambling Attitudes and Beliefs Survey (GABS) developed by Breen and Zuckerman (1999) measures a broad spectrum of such wrongly conceived beliefs and dysfunctional attitudes of gamblers. This widely acknowledged scale serves as an effective discriminator between problem gamblers and non-problem gamblers (Bouju et al., 2014; Breen, Kruedelbach, \& Walker, 2001; Grant \& Bowling, 2015; Tanner \& Mazmanian, 2016).

Addiction research identifies impulsivity and short-term orientation as additional prominent indicators of pathological gambling (Alessi \& Petry, 2003). Impulsive choices are characterized as an individual's motivational and decision-making style (Steward et al., 2017). Gamblers facing addiction problem do not highly value long-term effects, such as social relationships or job prospects (as they are delayed in time), as compared with perceived gambling benefits, which are immediate in nature (Andrade \& Petry, 2012). Delay discounting is one of the most widely utilized indices of choice impulsivity (Amlung, Vedelago, Acker, Balodis, \& MacKillop, 2017) and considered to be a component of a broader impulsivity construct (Anokhin, Golosheykin, Grant, \& Heath, 2011). Accordingly, pathological gamblers steeply discount monetary rewards as compared with various control groups (Castellani \& Rugle, 1995; Clarke, 2004; Petry, 2001; Petry \& Casarella, 1999). However, the quest for immediate gratification is a widespread human behavior (O'Donoghue \& Rabin, 2000), leading to the assumption that this personality trait can exert only a moderating influence on addiction problems.

In summary, previous studies investigated single effects of attitudes/beliefs or impulsivity on manifested problem gambling behavior, while largely ignoring the combined effects of short-term impulsivity and long-term attitude/beliefs on online gambling addiction. Therefore, this study attempts to fill this void in the literature by investigating relationships between attitudes and beliefs and online gambling addiction, moderated by the effect of 
impulsivity (as measured by delay discounting). Moreover, expanding prior studies (e.g., Grall-Bronnec et al., 2011; Jardin \& Wulfert, 2009; Neighbors, Lostutter, Larimer, \& Takushi, 2002), we differentiate five major sub-dimensions of GABS-emotions, chasing, luck, attitudes and strategies, as identified by Bouju et al. (2014) - to reveal their specific impact on online gambling addiction.

\section{Online gambling, gambling attitude and belief}

With advancements in technology enabling convenient and interactive access to myriad types of online gambling opportunities (Gainsbury et al., 2015; King \& Delfabbro, 2016; Monaghan, 2009), participation in online gambling has increased at an alarming rate (Cotte \& Latour, 2008; LaPlante, Nelson, LaBrie, \& Shaffer, 2009). The omnipresence and connected nature of online gambling supports an increased gambling frequency, often leading to gambling addiction (Gainsbury, Delfabbro, King, \& Hing, 2016; Griffiths, 2001; Sévigny, Cloutier, Pelletier, \& Ladouceur, 2005). Several large-scale studies reveal that as compare to terrestrial or land-based forms, online gambling results into increased risk of addiction (Gainsbury et al., 2012; Griffiths et al., 2009; King et al., 2010; Smith and Campbell, 2007; Wood and Williams, 2011).

Gambling-related attitudes, beliefs and emotions are key constructs of manifested gambling problems (Toneatto \& Millar, 2004). Breen and Zuckerman (1999) measured various cognitive biases and unfounded beliefs using the GABS to discriminate problem gamblers from non-problem gamblers. A shorter and multidimensional version of the GABS was recently introduced by Bouju et al. (2014). This version has sound psychometric properties and discriminates problem gamblers as efficiently as the original GABS (Bouju et al., 2014; Grant \& Bowling, 2015). Furthermore, it differentiates five dimensions of GABS: emotions, chasing, luck, attitudes and strategies. Considering the heterogeneous nature of these dimensions, we hypothesize that some dimensions may exacerbate addiction problems 
while others may limit the same depending on gamblers' need for immediate or delayed gratification.

Impulsivity is an important moderating effect of pathological gambling behavior (Alessi \& Petry, 2003). Studies in behavioral science widely used delay discounting as a measure of impulsive decision making (Anokhin et al., 2011; Bickel, Odum, \& Madden, 1999; Coffey, Gudleski, Saladin, \& Brady, 2003; MacKillop et al., 2011; Odum, 2011; Perry, Larson, German, Madden, \& Carroll, 2005).

Impulsivity has been defined as a personality trait of individual who act hastily or impatiently (Barratt, Patton, Greger Olsson, \& Zuker, 1981). Impulsive choices in human decision-making is operationalized by measuring delay discounting (Anokhin et al., 2011). Delay discounting is measured by a choice between a relatively smaller reward received instantly and a relatively larger reward in the distant future (Anokhin et al., 2011). According to Andrade and Petry (2012), the tendency to steeply discount the reward indicates incapacity to wait and thus impulsivity. Gamblers with severe addiction problem exhibit relatively high impulsivity scores (Petry, 2001; Toplak, Liu, MacPherson, Toneatto, \& Stanovich, 2007), and various studies showed that addicted gamblers differ from others with regard to the steep discount of monetary rewards (Alessi \& Petry, 2003; Dixon, Jacobs, \& Sanders, 2006; Ledgerwood, Alessi, Phoenix, \& Petry, 2009; Nigro \& Cosenza, 2016; Petry \& Casarella, 1999). However, the interplay between gambling attitudes and delay discounting has not been explored in the context of addiction. This is potentially critical as the quest for immediate rewards might counteract the long-term attitudes and beliefs of casual gamblers. Expanding this line of thinking, we derive five hypotheses and test them in the empirical part of the study.

\section{Effects of emotions and erroneous beliefs on gambling addiction}

Emotional factors are well established indicators of gambling addiction (Balodis, Lacadie, \& Potenza, 2012). Pathological gamblers score significantly lower in emotional stability than 
non-pathological gamblers (Chiu \& Storm, 2010). Accordingly, Ricketts and Macaskill (2003) found that gamblers seeking treatment reported emotional arousal that led to increased wagering. Experimental studies (Potenza et al., 2003), observations (Bouju et al., 2014) and surveys (Balodis et al., 2012) established significantly higher intensities of emotional responses among pathological gamblers as compared to control groups. Emotional factors also contribute to excessive gambling, as emotional arousal evoked by gambling allows gamblers to reach an increased level of emotional stimulation (Bouju et al., 2014; Zuckerman, 1994). Such emotions exist independent of impulsivity. Thus, we postulate a universal relationship between emotional arousal and gambling behavior as follows:

H1. In online gambling, emotional arousal is positively related to addiction regardless of impulsive behavior.

Chasing is one of the irrational behaviors prevalent among gamblers and marks a major step on the path to pathological gambling (Coventry \& Brown, 1993; Hodgins, Stea, \& Grant, 2011; Lesieur, 1979). Repeated bets are placed despite losses in the irrational belief of getting even or winning (Bouju et al., 2014; Svetieva \& Walker, 2008). Lesieur (1984) also found that as more is lost, the chase becomes more intense and the size of the bets often increases. This, in turn, results in more frequent involvement, higher monetary risk and increased persistence (Breen \& Zuckerman, 1999), characterizing the severity of addiction (T.-L. MacKay \& Hodgins, 2012; Orford, Sproston, \& Erens, 2003). Research has found that pathological gamblers scored higher on chasing behavior as compare to non-addicted respondents (Bouju et al., 2014; Coventry \& Norman, 1997) and that they also depict chasing behavior to win back the money they lost. Extending these coherent findings to the overall population level, the second hypothesis states the following:

H2. In online gambling, chasing is positively related to addiction regardless of impulsive behavior. 
Luck is an irrational belief in which an individual perceives an illusory sense of control (Walker, 1992) over an event with unpredictable results (Darke \& Freedman, 1997). Rather than recognizing luck as an external or unstable factor, and thus uncontrollable in nature (Darke \& Freedman, 1997), the person may regard luck as an internal and stable factor, leading to illusionary control, optimism and confidence (Baron \& Hershey, 1988; Darke \& Freedman, 1997). Gamblers with severe addiction problem exhibit such highly irrational beliefs in their own ability to affect the likelihood of winning (Hoorens, 1994; Wohl \& Enzle, 2003; Wohl, Young, \& Hart, 2007). Kim, Kwon, and Hyun (2015) found that gamblers with an irrational belief in good luck gamble more frequently, spend more money and have higher expectations of winning than those with a relatively lower level of belief in their luck. Accordingly, the third hypothesis is as follows:

H3. In online gambling, belief in luck is positively related to the extent of addiction regardless of impulsive behavior.

\section{Effects of attitudes on online gambling addiction}

Attitudes are relatively enduring predispositions to act (Oskamp \& Schultz, 2005) which have been defined in context of gambling as a set of convictions that are believed to increase the probability of winning (Bouju et al., 2014). Such attitudes were identified as precursor to addiction problems (Chiu \& Storm, 2010; Derevensky, Sklar, Gupta, \& Messerlian, 2010; Kassinove, 1998; Sullivan Kerber, 2005). Gambling-related attitudes include acting calm even when loosing, feeling confident and acting in a certain way when winning (Bouju et al., 2014). Some studies show that such attitudes toward gambling are indicative of gambling addiction (Chiu \& Storm, 2010; Derevensky et al., 2010; Sullivan Kerber, 2005).

Bouju et al. (2014) argued that gambling attitudes and related strategies are indicators of a (wrongly) perceived internal locus of control in gambling. While this misperception is likely true for problem gamblers, both attitudes and strategies might protect against erratic gambling behavior in the normal population. This holds because rules and predispositions 
should help online gamblers overcome an urge to act upon gambling outcomes. We thus argue that the effects of attitudes on gambling addiction are dependent on gamblers' impulsivity: that is, feeling confident and acting in certain ways should be detrimental for impulsive gamblers because these factors are likely to intensify impulsive reaction to gambling experiences. In contrast, these factors should protect against addiction for less impulsive gamblers, as they offer the possibility to reflect and react in a more controlled way. Thus, impulsivity, as measured with the help of delay discounting, is likely to moderate the empirical relationship between attitudes and addiction.

H4. Online gambling attitudes increase the extent of addiction only for gamblers seeking smaller and immediate gratification, not for those seeking larger and delayed rewards.

Finally, the use of strategies in gambling is characteristic of pathological gamblers (Grant \& Bowling, 2015). This phenomenon, however, is not limited to problem gamblers. Gamblers at large believe that skill and use of certain strategies can generate higher chances of winning the game, while in reality luck plays a dominant role (Tomei, Bamert, \& Sani, 2017; Toneatto, Blitz-Miller, Calderwood, Dragonetti, \& Tsanos, 1997). In games such as Roulette, gamblers largely believe that particular game-specific strategies and tactics can lead to increased odds of winning (Tomei et al., 2017). However, research has also shown that in games such as poker, being more adaptive to strategic changes enhances a person's chances of winning (DeDonno \& Detterman, 2008; T. MacKay, Bard, Bowling, \& Hodgins, 2014). In line hereto, Bouju et al. (2014) also opined that having sound gambling strategies may increase the probability of winning. Thus, strategies cannot always be classified as misleading, as their effect depends on whether they are based on factual issues or an illusion.

We argue that the possible effects of strategies on gambling behavior are contingent on gamblers' impulsivity, measured by delay discounting. A choice of a smaller and immediate sum reward depicts an impulsive and short-term orientation, while preference for a larger and 
delayed sum reward indicates self-control (Green, Fry, \& Myerson, 1994; Green \& Myerson, 2004; Logue, 1988). Thus, long-term strategies should not influence actual gambling behavior of highly impulsive and short-term-oriented gamblers:

H5. Factual (illusory) strategies are negatively (positively) related to addiction only for online gamblers seeking larger and delayed rewards.

\section{Methodology}

We collected data as part of a survey investigating the gaming and gambling sector by means of a structured, non-disguised questionnaire. Between April and May 2015, a professional market research agency collected responses by using one of the prominent online panels based in Germany. Online panel respondents who had indulged in online gambling activities within the last four weeks before the survey were randomly selected from all of Germany's 16 states. Responses from 500 gamblers playing online gambles were collected. All the procedures performed in the study involving human participants were in accordance with the ethical standards of the University of Hamburg. The online panel participants were provided possibilities to collect points as reward for participation in the survey with the chance to convert it into gift voucher or cash. We applied a double-hurdle regression model to analyze the relationship between long-term attitudes and beliefs on online gambling addiction based on the methodology developed by Cragg (1971). Statistically speaking, a double-hurdle model combines a probit model to separate the crossing of a first hurdle from a truncated normal model that predicts the intensity effects on a dependent variable (here: online gambling addiction) in a second hurdle (Cragg, 1971). This procedure joins a univariate probit model in the first tier with a truncated regression model for the second tier (Mussa, 2014; Wooldridge, 2010). Combining both methods in Cragg (1971) double-hurdle model leads to an increase in statistical efficiency as compared to two consecutive assessments (Zhang, Huang, Lin, \& Epperson, 2008). The double-hurdle model is implemented by the Stata command dhreg developed by Engel and Moffatt (2014). 
The model assumes that an online gambler have to cross two hurdles to be considered addicted. Of the 500 online gamblers participating in the survey, we labeled those who did not pass the first hurdle as "unsusceptible to any addiction" and those who passed the first hurdle as "plausibly affected by addiction" (Trivedi \& Teichert, 2017). Table 1 presents detailed demographic information about the respondents. The respondents are primarily playing online lotteries $(25.8 \%)$ closely followed by poker (23.6\%), sports betting (16.2\%), casino games $(12.3 \%)$ and other games $(22.1 \%)$. About $28 \%$ of the respondents indulge in online gambling once a week, $43.2 \%$ plays 2 or 3 times a week and remaining playing for 5 days or more in a week. In each session, about $53 \%$ of respondents play less than an hour, $40.4 \%$ plays between one to three hours and remaining playing for more than 3 hours.

< insert Table 1 here >

We measured gambling attitude and behavior with the GABS-23 scale adopted from Bouju et al. (2014). GABS-23 was developed based upon original 35-items self-report questionnaire to assess irrational belief and attitudes about gambling (Breen \& Zuckerman, 1999) with sound psychometric properties discriminating non-problem gamblers from problem gamblers as effectively as the original GABS (Bouju et al., 2014). We measured delay discounting with the help of a scale developed by Reimers, Maylor, Stewart, and Chater (2009). Respondents were presented with a hypothetical delay-discounting binary choice between 45 euros in three days and 70 euros in three months. Internet gambling addiction was measured with nine items adopted from Pontes and Griffiths (2015) that has been primarily designed to measure internet gaming disorder. It is to be noted that in the addiction scale developed by Pontes and Griffiths (2015), scores are obtained by summing the respondent's answers and total scores range from 9 to 45 , with higher scores being indicative of severity of disorder and detrimental effects to the respondent's life. Only for studies pursuing strictly clinic diagnosis, Pontes and Griffiths (2015) further inform that these 9 items could be altered into the traditional yes/no format. Thus, the scale could also be used for symptom as well as 
clinical diagnosis purpose. Research assistants performed and verified back translation of the scales from English to German. Answers were recorded on a five-point Likert-type scale, anchored by "very often" (5) and "never" (1), in which the rating (3) was for "sometimes."

\section{Results}

A confirmatory factor analysis (CFA) assessed the adequacy and quality of the GABS-23 scale by assessing reliability as well as convergent and discriminant validity of the measurement model. Multiple indicators served to assess the goodness of fit: $\chi^{2} / d f<4$, comparative fit index $(\mathrm{CFI}) \geq 0.9$, Tucker-Lewis index (TLI) $\geq 0.9$ and root mean square error of approximation (RMSEA) $\leq 0.08$ (Byrne, 2001). Maximum likelihood estimation method was used for CFA. All goodness-of-fit statistics $\left(\chi^{2}=865.904 ; d f=272 ; p<0.001\right.$; $\left.\chi^{2} / d f=3.183 ; \mathrm{CFI}=0.895 ; \mathrm{TLI}=0.870 ; \mathrm{RMSEA}=0.066\right)$ are close to or within acceptable limits. Composite reliability values are above the recommended level of 0.70 , confirming the scale's convergent validity. In addition, the average variance extracted for each dimension always exceeds the minimum acceptable level of 0.50 (Hair, Black, Babin, Anderson, \& Tatham, 1998). In sum, the results of CFA confirm the reliability and validity of the fivefactor structure proposed by Bouju et al. (2014). Thus, the five dimensions of GABS as suggested by Bouju et al. (2014) are substantiated in our study.

We applied a double-hurdle regression model Cragg (1971) to measure the multivariate relationships of the five dimensions of GABS with Internet gambling addiction. The double-hurdle regression model consists of two equations: whether an online gambler perceives any addiction at all (the "first hurdle") and the extent of his or her addiction (the “second hurdle") (Wooldridge, 2010). By separating both stages, the model takes into account that addiction problems might not be severe for a subset of gamblers, whatever their circumstances might be. A stage model also helps to account for methodological problems of investigating causal factors in cross-sectional data (Sutton, 2000). Recently, Rude, Surry, and Kron (2014) successfully used such double-hurdle modeling in gambling. 
Of the 500 online gamblers who participated in the study, 229 are left-censored with a sum score of 9 on the nine items of the addiction scale. They thus do not exhibit any addiction-related problems at all. These descriptives are in line with previous studies in which between 10 and 65 percent of respondents are identified as problem gamblers (Ladd \& Petry, 2002; Matthews, Farnsworth, \& Griffiths, 2009; Petry, 2006). The 271 respondents who pass the first hurdle have an average sum value of 18.28 on the addiction scale. Out of them, 174 selected the option of 45 euros in three days (smaller and immediate reward) and the remaining 97 online gamblers opted to receive 70 euros in three months (larger and delayed reward). As expected, the group of impulsive gamblers is thus larger than the group of more patient and less impulsive gamblers.

Table 2 summarizes the findings of the estimation models. Estimation results obtained from separate probit and tobit models are reported for the purpose of comparison only. This is followed by the results of the double-hurdle regression model for the 271 online gamblers who cross the first hurdle.

\section{< insert Table 2 here >}

According to Hypothesis 1, emotional arousal felt by online gamblers should relate to addiction problems regardless of impulsive behavior. Results show a positive and statistically significant relationship between emotional arousal and addiction for both groups of online gamblers, those who selected the smaller and immediate sum reward $(\beta=0.857, p<.001)$ and those who were ready to wait longer to receive a larger reward $(\beta=0.510, p<.001)$. Similarly and in support of Hypothesis 2, chasing behavior relates to increased addiction severity among gamblers regardless of impulsivity (smaller and immediate sum reward: $\beta=0.546, p<$ .001 ; larger and delayed sum reward: $\beta=0.439, p<.001)$. Hypothesis 3 postulates that an online gambler's belief in luck relates to addiction regardless of impulsive behavior. The results provide empirical evidence confirming this hypothesis, but only for online gamblers seeking a larger and delayed sum reward $(\beta=0.250, p<.05)$. Hypothesis 4 states that attitude 
relate negatively to addiction only for gamblers seeking a smaller and immediate reward. The results provide support for this hypothesis, as we find a statistically significant and negative link between attitudes and addiction among gamblers seeking a larger and delayed reward $(\beta$ $=-0.271, p<.01)$. Finally, Hypothesis 5 postulates that factual strategies matter only for gamblers seeking a larger and delayed sum reward. However, the results indicate that factual strategies relate negatively to addiction for gamblers seeking a sooner and immediate sum $\operatorname{reward}(\beta=-0.206, p<.05)$.

\section{Discussion and implications}

Prior research suggests targeting specific gambling attitudes and beliefs to help problem gamblers (Bouju et al., 2014; Breen et al., 2001). Doing so requires to differentiate the various long-term attitudes and beliefs and to relate them separately to gambling problems. Departing from previous studies that assessed the overall relationship of gambling attitudes and beliefs with addiction (e.g., Grall-Bronnec et al., 2011; Grant \& Bowling, 2015), the present study disentangles five sub-dimensions of GABS and hypothesizes that some dimensions relate positively to gambling addiction while others might limit them. In addition, the role of impulsivity on pathological gambling severity (Andrade \& Petry, 2012; Cosenza \& Nigro, 2015; Madden, Francisco, Brewer, \& Stein, 2011) is assessed by measuring delay discounting (seeking a small and immediate reward versus a larger and later reward).

We used a double-hurdle model to separately assess the relationship of the five dimensions of GABS with addiction for gamblers seeking both smaller and immediate sum rewards and larger and delayed sum rewards. The results as depicted in Table III show that emotions and chasing behavior are linked to addiction for online gamblers who have crossed the first hurdle, regardless of their impulsivity.

< insert Table 3 here >

While belief in luck relates to severe addiction problem, gambling attitudes relate to lower addiction among online gamblers seeking larger and delayed sum rewards. A negative 
relationship between factual strategies and the extent of addiction is only observed for online gamblers who seek smaller and immediate sum rewards.

We found that emotional arousal relates to higher addiction severity among online gamblers regardless of their impulsivity. This finding has received support in previous literature: emotional arousal results in increased excitement and gambling intensity (Balodis et al., 2012; Potenza et al., 2003): An emotionally charged gambler acts on instinct or gut feeling, thus suppressing reasoning or logical thinking based on the odds of winning. This has been shown to increase the frequency of bets as well as within-session gambling, which may ultimately result in severe gambling problems. Thus, gamblers should avoid online gambling activities immediately after experiencing an intense emotion or critical life event. A cognitive assessment of the odds and an avoidance of playing in an emotional aroused state may help online gamblers limit potential addiction problems.

Chasing behavior also relates to higher addiction regardless of online gamblers' impulsivity. This finding is in line with previous studies (Bouju et al., 2014; Svetieva \& Walker, 2008). Chasing may result into higher losses and associated negative outcomes (Breen \& Zuckerman, 1999). Consequently, from a policy maker's perspective, trying to control the chasing behavior with active policy intervention may effectively control a gambler's chasing behavior.

Prior research indicates that pathological gamblers have an irrational belief in luck and its effect on winning (Chiu \& Storm, 2010; Wohl \& Enzle, 2003). The current study found that an irrational belief in luck coincides with higher addiction problems. This finding is in line with previous studies where it has been observed that those gamblers who believed in luck were more confident and bet more with higher loss (e.g., Darke \& Freedman, 1997; Kim et al., 2015) as they often regard luck as a personal attribute (Darke \& Freedman, 1997; Griffiths, 1994; Wohl, Young, \& Hart, 2005). However, the relationship between luck and addiction was observed only among gamblers who seek larger and delayed sum rewards. This 
finding requires further investigation, as this relationship is not significant among online gamblers plausibly affected by addiction who seek smaller and immediate sum rewards.

A negative relationship between attitude and addiction was found among online gamblers seeking larger and delayed sum rewards. This result confirms the findings of Delfabbro and Thrupp (2003) but contradicts those of Chiu and Storm (2010) and Derevensky et al. (2010). Whereas these studies considered all pathological gamblers, the current study divided gamblers into two groups based on impulsivity. Gamblers willing to wait to receive larger rewards seem to have a greater reflectivity and controlled behavior that has led to a reduction of potential addiction problems. This finding identifies delay discounting as an important moderator of the relationship between attitudes and online gambling addiction.

This study has several limitations. The specific effects of the five factors of the GABS may vary across types of games played online and across specific media platforms used. Future studies might also benefit by measuring delay discounting with a continuous scale rather than a binary choice. We have used IGD scale developed by Pontes and Griffiths (2015) to measure gambling addiction that primarily do not measure between-session loss chasing. Moreover, Pontes and Griffiths (2015) also does not clearly outline where the gradient of severity begins and fails to discriminate between gamblers that are severely affected from the ones that may occasionally lapse in and out of controlled behavior. It is also to be noted that some of the items of DSM criteria has been recently criticized as one without sufficient power to discriminate addiction behavior. While the double-hurdle regression model serves as a state-of-the-art model to disentangle effects in a two-stage model, the setting of a cross-sectional survey limits inferences of causality. This study only considers effects of gambling attitude and behavior on online gambling addiction and these may differ in the context of offline gambling. Last but not least, the use of self-reported measurements constitutes another inherent limitation of the study. 
Complementing previous studies, we differentiate the association of five subdimensions of GABS on online gambling addiction. With this, the study is the first to show the moderating effects of delay discounting on the link between long-term attitudes and beliefs and gambling problems. Only emotional arousal and chasing behavior relates to addiction problems irrespective of gamblers' impulsivity choices. In contrast, attitude has negative association with addiction for gamblers seeking large and delayed sum reward, while strategies have negative association with addiction for gamblers looking for smaller and immediate sum reward. These findings may help public policy makers and practitioners working in the gambling addiction domain to design more tailored addiction prevention programs. Future studies can build on these results by designing experimental settings with longitudinal design to validate and further explore these associations. Moreover, future research is encouraged to investigate more complex delay discounting choice scenarios, e.g., by use of neurocognitive approach to bring further insights about the facets of impulsivity and it's relation with gambling addiction.

\section{Reference}

Alessi, S., \& Petry, N. (2003). Pathological gambling severity is associated with impulsivity in a delay discounting procedure. Behavioural Processes, 64(3), 345-354.

Amlung, M., Vedelago, L., Acker, J., Balodis, I., \& MacKillop, J. (2017). Steep delay discounting and addictive behavior: a meta-analysis of continuous associations. Addiction, 112(1), 51-62.

Andrade, L. F., \& Petry, N. M. (2012). Delay and probability discounting in pathological gamblers with and without a history of substance use problems. Psychopharmacology, 219(2), 491-499.

Anokhin, A. P., Golosheykin, S., Grant, J. D., \& Heath, A. C. (2011). Heritability of delay discounting in adolescence: a longitudinal twin study. Behavior genetics, 41(2), 175183. 
Balodis, I. M., Lacadie, C. M., \& Potenza, M. N. (2012). A preliminary study of the neural correlates of the intensities of self-reported gambling urges and emotions in men with pathological gambling. Journal of Gambling Studies, 28(3), 493-513.

Baron, J., \& Hershey, J. C. (1988). Outcome bias in decision evaluation. Journal of personality and social psychology, 54(4), 569.

Barratt, E. S., Patton, J., Greger Olsson, N., \& Zuker, G. (1981). Impulsivity and paced tapping (Vol. 13).

Bickel, W. K., Odum, A. L., \& Madden, G. J. (1999). Impulsivity and cigarette smoking: delay discounting in current, never, and ex-smokers. Psychopharmacology, 146(4), 447-454.

Bouju, G., Hardouin, J.-B., Boutin, C., Gorwood, P., Le Bourvellec, J.-D., Feuillet, F., . . . Grall-Bronnec, M. (2014). A shorter and multidimensional version of the Gambling Attitudes and Beliefs Survey (GABS-23). Journal of Gambling Studies, 30(2), 349367.

Breen, R. B., Kruedelbach, N. G., \& Walker, H. I. (2001). Cognitive changes in pathological gamblers following a 28-day inpatient program. Psychology of Addictive Behaviors, 15(3), 246.

Breen, R. B., \& Zuckerman, M. (1999). Chasing'in gambling behavior: Personality and cognitive determinants. Personality and Individual Differences, 27(6), 1097-1111.

Castellani, B., \& Rugle, L. (1995). A comparison of pathological gamblers to alcoholics and cocaine misusers on impulsivity, sensation seeking, and craving. International journal of the addictions, 30(3), 275-289.

Chiu, J., \& Storm, L. (2010). Personality, perceived luck and gambling attitudes as predictors of gambling involvement. Journal of Gambling Studies, 26(2), 205-227.

Clarke, D. (2004). Impulsiveness, locus of control, motivation and problem gambling. Journal of Gambling Studies, 20(4), 319-345.

Coffey, S. F., Gudleski, G. D., Saladin, M. E., \& Brady, K. T. (2003). Impulsivity and rapid discounting of delayed hypothetical rewards in cocaine-dependent individuals. Experimental and clinical psychopharmacology, 11(1), 18.

Cosenza, M., \& Nigro, G. (2015). Wagering the future: Cognitive distortions, impulsivity, delay discounting, and time perspective in adolescent gambling. Journal of Adolescence, 45, 56-66.

Cotte, J., \& Latour, K. A. (2008). Blackjack in the kitchen: Understanding online versus casino gambling. Journal of Consumer Research, 35(5), 742-758. 
Coventry, K. R., \& Brown, R. (1993). Sensation seeking, gambling and gambling addictions. Addiction, 88(4), 541-554.

Coventry, K. R., \& Norman, A. C. (1997). Arousal, sensation seeking and frequency of gambling in off-course horse racing bettors. British Journal of Psychology, 88(4), 671681.

Cragg, J. G. (1971). Some statistical models for limited dependent variables with application to the demand for durable goods. Econometrica: Journal of the Econometric Society, 829-844.

Darke, P. R., \& Freedman, J. L. (1997). Lucky events and beliefs in luck: Paradoxical effects on confidence and risk-taking. Personality and Social Psychology Bulletin, 23(4), 378388.

DeDonno, M. A., \& Detterman, D. K. (2008). Poker is a skill. Gaming Law Review, 12(1), 31-36.

Delfabbro, P., \& Thrupp, L. (2003). The social determinants of youth gambling in South Australian adolescents. Journal of Adolescence, 26(3), 313-330.

Derevensky, J., Sklar, A., Gupta, R., \& Messerlian, C. (2010). An empirical study examining the impact of gambling advertisements on adolescent gambling attitudes and behaviors. International Journal of Mental Health and Addiction, 8(1), 21-34.

Dixon, M. R., Jacobs, E. A., \& Sanders, S. (2006). Contextual control of delay discounting by pathological gamblers. Journal of applied behavior analysis, 39(4), 413-422.

Engel, C., \& Moffatt, P. G. (2014). dhreg, xtdhreg, and bootdhreg: Commands to implement double-hurdle regression. Stata Journal, 14(4), 778-797.

Gainsbury, Delfabbro, P., King, D. L., \& Hing, N. (2016). An exploratory study of gambling operators' use of social media and the latent messages conveyed. Journal of Gambling Studies, 32(1), 125-141.

Gainsbury, Russell, A., Hing, N., Wood, R., Lubman, D., \& Blaszczynski, A. (2015). How the Internet is changing gambling: Findings from an Australian prevalence survey. Journal of Gambling Studies, 31(1), 1-15.

Grall-Bronnec, M., Wainstein, L., Augy, J., Bouju, G., Feuillet, F., Venisse, J.-L., \& SebilleRivain, V. (2011). Attention deficit hyperactivity disorder among pathological and atrisk gamblers seeking treatment: a hidden disorder. European addiction research, 17(5), 231-240.

Grant, L. D., \& Bowling, A. C. (2015). Gambling attitudes and beliefs predict attentional bias in non-problem gamblers. Journal of Gambling Studies, 31(4), 1487-1503. 
Green, L., Fry, A. F., \& Myerson, J. (1994). Discounting of delayed rewards: A life-span comparison. Psychological science, 5(1), 33-36.

Green, L., \& Myerson, J. (2004). A discounting framework for choice with delayed and probabilistic rewards. Psychological bulletin, 130(5), 769.

Griffiths, M. D. (1994). The role of cognitive bias and skill in fruit machine gambling. British Journal of Psychology, 85(3), 351-369.

Griffiths, M. D. (2001). Internet gambling: Preliminary results of the first UK prevalence study. Journal of Gambling Issues(5).

Hair, J. F., Black, W. C., Babin, B. J., Anderson, R. E., \& Tatham, R. L. (1998). Multivariate data analysis (Vol. 5): Prentice hall Upper Saddle River, NJ.

Hodgins, D. C., Stea, J. N., \& Grant, J. E. (2011). Gambling disorders. The Lancet, 378(9806), 1874-1884.

Hoorens, V. (1994). Unrealistic optimism in health and safety risks.

Jardin, B., \& Wulfert, E. (2009). The use of messages in altering risky gambling behavior in college students: An experimental analogue study. The American journal on addictions, 18(3), 243-247.

Kassinove, J. I. (1998). Development of the gambling attitude scales: Preliminary findings. Journal of clinical psychology, 54(6), 763-771.

Kim, S.-R., Kwon, Y.-S., \& Hyun, M.-H. (2015). The effects of belief in good luck and counterfactual thinking on gambling behavior. Journal of behavioral addictions, 4(4), 236-243.

King, D. L., \& Delfabbro, P. H. (2016). Early exposure to digital simulated gambling: A review and conceptual model. Computers in human behavior, 55, 198-206.

Ladd, G. T., \& Petry, N. M. (2002). Disordered gambling among university-based medical and dental patients: a focus on Internet gambling. Psychology of Addictive Behaviors, $16(1), 76$.

LaPlante, D. A., Nelson, S. E., LaBrie, R. A., \& Shaffer, H. J. (2009). Disordered gambling, type of gambling and gambling involvement in the British Gambling Prevalence Survey 2007. The European Journal of Public Health, 21(4), 532-537.

Ledgerwood, D. M., Alessi, S. M., Phoenix, N., \& Petry, N. M. (2009). Behavioral assessment of impulsivity in pathological gamblers with and without substance use disorder histories versus healthy controls. Drug and alcohol dependence, 105(1), 8996. 
Lesieur, H. R. (1979). The compulsive gambler's spiral of options and involvement. Psychiatry, 42(1), 79-87.

Lesieur, H. R. (1984). The Chase: the career of the compulsive gambler (Rochester, VT, Schenkman).

Logue, A. W. (1988). Research on self-control: An integrating framework. Behavioral and Brain Sciences, 11(4), 665-679.

MacKay, T.-L., \& Hodgins, D. C. (2012). Cognitive distortions as a problem gambling risk factor in Internet gambling. International Gambling Studies, 12(2), 163-175.

MacKay, T., Bard, N., Bowling, M., \& Hodgins, D. (2014). Do pokers players know how good they are? Accuracy of poker skill estimation in online and offline players. Computers in human behavior, 31, 419-424.

MacKillop, J., Amlung, M. T., Few, L. R., Ray, L. A., Sweet, L. H., \& Munafò, M. R. (2011). Delayed reward discounting and addictive behavior: a meta-analysis. Psychopharmacology, 216(3), 305-321.

Madden, G. J., Francisco, M. T., Brewer, A. T., \& Stein, J. S. (2011). Delay discounting and gambling. Behavioural Processes, 87(1), 43-49.

Matthews, N., Farnsworth, B., \& Griffiths, M. D. (2009). A pilot study of problem gambling among student online gamblers: mood states as predictors of problematic behavior. CyberPsychology \& Behavior, 12(6), 741-745.

Monaghan, S. (2009). Responsible gambling strategies for Internet gambling: The theoretical and empirical base of using pop-up messages to encourage self-awareness. Computers in human behavior, 25(1), 202-207.

Mussa, R. (2014). Extending the Oaxaca-Blinder decomposition to the independent double hurdle model: with application to parental spending on education in Malawi. Studies in Economics and Econometrics, 38(3), 39-54.

Neighbors, C., Lostutter, T. W., Larimer, M. E., \& Takushi, R. Y. (2002). Measuring gambling outcomes among college students. Journal of Gambling Studies, 18(4), 339360.

Nigro, G., \& Cosenza, M. (2016). Living in the now: Decision-making and delay discounting in adolescent gamblers. Journal of Gambling Studies, 32(4), 1191-1202.

O'Donoghue, T., \& Rabin, M. (2000). The economics of immediate gratification. Journal of Behavioral Decision Making, 13(2), 233.

Odum, A. L. (2011). Delay discounting: trait variable? Behavioural Processes, 87(1), 1-9. 
Orford, J., Sproston, K., \& Erens, B. (2003). SOGS and DSM-IV in the British Gambling Prevalence Survey: Reliability and factor structure. International Gambling Studies, 3(1), 53-65.

Oskamp, S., \& Schultz, P. W. (2005). Attitudes and opinions: Psychology Press.

Perry, J. L., Larson, E. B., German, J. P., Madden, G. J., \& Carroll, M. E. (2005). Impulsivity (delay discounting) as a predictor of acquisition of IV cocaine self-administration in female rats. Psychopharmacology, 178(2-3), 193-201.

Petry, N. M. (2001). Pathological gamblers, with and without substance abuse disorders, discount delayed rewards at high rates. Journal of abnormal psychology, 110(3), 482.

Petry, N. M. (2006). Should the scope of addictive behaviors be broadened to include pathological gambling? Addiction, 101(s1), 152-160.

Petry, N. M., \& Casarella, T. (1999). Excessive discounting of delayed rewards in substance abusers with gambling problems. Drug and alcohol dependence, 56(1), 25-32.

Pontes, H. M., \& Griffiths, M. D. (2015). Measuring DSM-5 internet gaming disorder: Development and validation of a short psychometric scale. Computers in Human Behavior, 45, 137-143.

Potenza, M. N., Steinberg, M. A., Skudlarski, P., Fulbright, R. K., Lacadie, C. M., Wilber, M. K., . . . Wexler, B. E. (2003). Gambling urges in pathological gambling: a functional magnetic resonance imaging study. Archives of general psychiatry, 60(8), 828-836.

Reimers, S., Maylor, E. A., Stewart, N., \& Chater, N. (2009). Associations between a oneshot delay discounting measure and age, income, education and real-world impulsive behavior. Personality and individual differences, 47(8), 973-978.

Ricketts, T., \& Macaskill, A. (2003). Gambling as emotion management: Developing a grounded theory of problem gambling. Addiction Research \& Theory, 11(6), 383-400.

Rude, J., Surry, Y., \& Kron, R. (2014). A generalized double-hurdle model of Swedish gambling expenditures. Applied Economics, 46(34), 4151-4163.

Sévigny, S., Cloutier, M., Pelletier, M.-F., \& Ladouceur, R. (2005). Internet gambling: Misleading payout rates during the "demo" period. Computers in human behavior, 21(1), 153-158.

Steward, T., Mestre-Bach, G., Fernández-Aranda, F., Granero, R., Perales, J. C., Navas, J. F., ... Martín-Romera, V. (2017). Delay discounting and impulsivity traits in young and older gambling disorder patients. Addictive behaviors, 71, 96-103.

Sullivan Kerber, C. (2005). Problem and pathological gambling among college athletes. Annals of Clinical Psychiatry, 17(4), 243-247. 
Sutton, S. (2000). Interpreting cross-sectional data on stages of change. Psychology and Health, 15(2), 163-171.

Svetieva, E., \& Walker, M. (2008). Inconsistency between concept and measurement: the Canadian Problem Gambling Index (CPGI). Journal of Gambling Issues(22), 157-173.

Tanner, J., \& Mazmanian, D. (2016). Gambling attitudes and beliefs associated with problem gambling: the cohort effect of Baby Boomers. International Gambling Studies, 16(1), 98-115.

Tomei, A., Bamert, A., \& Sani, A.-M. (2017). Misbeliefs about gambling in a convenience sample from the general population. Journal of Gambling Studies, 33(3), 899-906.

Toneatto, T., Blitz-Miller, T., Calderwood, K., Dragonetti, R., \& Tsanos, A. (1997). Cognitive distortions in heavy gambling. Journal of Gambling Studies, 13(3), 253-266.

Toneatto, T., \& Millar, G. (2004). Assessing and treating problem gambling: Empirical status and promising trends. The Canadian Journal of Psychiatry, 49(8), 517-525.

Toplak, M. E., Liu, E., MacPherson, R., Toneatto, T., \& Stanovich, K. E. (2007). The reasoning skills and thinking dispositions of problem gamblers: A dual-process taxonomy. Journal of Behavioral Decision Making, 20(2), 103-124.

Trivedi, R. H., \& Teichert, T. (2017). The Janus-Faced Role of Gambling Flow in Addiction Issues. Cyberpsychology, Behavior, and Social Networking, 20(3), 180-186.

Wohl, M. J., \& Enzle, M. E. (2003). The effects of near wins and near losses on selfperceived personal luck and subsequent gambling behavior. Journal of Experimental Social Psychology, 39(2), 184-191.

Wohl, M. J., Young, M. M., \& Hart, K. E. (2005). Untreated young gamblers with gamespecific problems: Self-concept involving luck, gambling ecology and delay in seeking professional treatment. Addiction Research \& Theory, 13(5), 445-459.

Wohl, M. J., Young, M. M., \& Hart, K. E. (2007). Self-perceptions of dispositional luck: Relationship to DSM gambling symptoms, subjective enjoyment of gambling and treatment readiness. Substance Use \& Misuse, 42(1), 43-63.

Wooldridge, J. M. (2010). Econometric analysis of cross section and panel data: MIT press.

Zhang, F., Huang, C. L., Lin, B. H., \& Epperson, J. E. (2008). Modeling fresh organic produce consumption with scanner data: a generalized double hurdle model approach. Agribusiness, 24(4), 510-522.

Zuckerman, M. (1994). Behavioral expressions and biosocial bases of sensation seeking: Cambridge university press. 
Table I

Demographic information about respondents

\begin{tabular}{|l|l|l|l|}
\hline Variable & & Frequency & $\%$ \\
\hline Gender & Male & 264 & 52.8 \\
& Female & 236 & 47.2 \\
\hline Monthly household & Less than 1000 Euro & 29 & 5.8 \\
& 1000 to less than 1500 Euro & 53 & 10.6 \\
& 1500 to less than 2000 Euro & 75 & 15.0 \\
& 2000 to less than 2500 Euro & 66 & 13.2 \\
& 2500 to less than 3000 Euro & 75 & 15.0 \\
& 3000 Euro and more & 155 & 31.0 \\
& Not specified & 47 & 9.4 \\
\hline Marital status & Married & 230 & 46 \\
& Single & 118 & 23.6 \\
& Unmarried - in a relationship & 100 & 20 \\
& Divorced/widowed & 52 & 10.4 \\
\hline Employment status & Still in education & 24 & 4.8 \\
& Employed in full-time & 285 & 57 \\
& Employed in part-time & 62 & 12.4 \\
& Self-employed & 31 & 6.2 \\
& Seeking work & 21 & 4.2 \\
& Retired & 50 & 10.0 \\
& Housewife / Houseman & 28 & 5.4 \\
\hline Education & Elementary school & 73 & 14.6 \\
& Secondary school & 168 & 33.6 \\
& Baccalaureate, without com- & 129 & 25.8 \\
& pleted degree & \\
\hline
\end{tabular}




\begin{tabular}{|l|l|l|l|}
\hline & $\begin{array}{l}\text { Completed degree of technical } \\
\text { university or university } \\
\text { Others }\end{array}$ & 126 & 25.2 \\
\hline
\end{tabular}


Table II. Double-hurdle regression model.

\begin{tabular}{|c|c|c|c|c|c|c|c|c|c|c|c|c|}
\hline & \multicolumn{6}{|c|}{$\begin{array}{c}\text { Double-hurdle model estimates } \\
\text { (45 euros in } 3 \text { days: Smaller and immediate sum reward) }\end{array}$} & \multicolumn{6}{|c|}{$\begin{array}{c}\text { Double-hurdle model estimates } \\
\text { (70 euros in } 3 \text { months: Larger and delayed sum reward) }\end{array}$} \\
\hline & \multicolumn{2}{|c|}{$\begin{array}{l}\text { Probit model: } \\
\text { DV = Addiction }\end{array}$} & \multicolumn{2}{|c|}{$\begin{array}{l}\text { Tobit model: } \\
\text { DV = Addiction }\end{array}$} & \multicolumn{2}{|c|}{$\begin{array}{c}\text { Second hurdle } \\
\text { (Plausibly affected } \\
\text { by initiatory } \\
\text { addiction issues): } \\
\text { DV = Addiction }\end{array}$} & \multicolumn{2}{|c|}{$\begin{array}{l}\text { Probit model: } \\
\text { DV = Addiction }\end{array}$} & \multicolumn{2}{|c|}{$\begin{array}{l}\text { Tobit model: } \\
\text { DV = Addiction }\end{array}$} & \multicolumn{2}{|c|}{$\begin{array}{c}\text { Second hurdle } \\
\text { (Plausibly affected } \\
\text { by initiatory addiction } \\
\text { issues): } \\
\text { DV = Addiction }\end{array}$} \\
\hline Variable & Coefficient & $\begin{array}{l}\text { Std. } \\
\text { Error }\end{array}$ & Coefficient & $\begin{array}{l}\text { Std. } \\
\text { Error }\end{array}$ & Coefficient & $\begin{array}{l}\text { Std. } \\
\text { Error }\end{array}$ & Coefficient & $\begin{array}{l}\text { Std. } \\
\text { Error }\end{array}$ & Coefficient & $\begin{array}{l}\text { Std. } \\
\text { Error }\end{array}$ & Coefficient & $\begin{array}{l}\text { Std. } \\
\text { Error }\end{array}$ \\
\hline Emotions & $0.820^{* * *}$ & 0.143 & $0.915^{* * *}$ & 0.122 & $0.857^{* * *}$ & 0.122 & $0.471^{* *}$ & 0.177 & $0.539 * * *$ & 0.130 & $0.510 * * *$ & 0.126 \\
\hline Strategies & -0.205 & 0.111 & $-0.202 *$ & 0.099 & $-0.206^{*}$ & 0.095 & 0.261 & 0.154 & 0.074 & 0.121 & 0.076 & 0.144 \\
\hline Coefficient & 0.069 & 0.081 & $-0.618^{* * *}$ & 0.083 & $-0.572^{* * *}$ & 0.080 & $0.325^{* *}$ & 0.110 & $-0.386^{* * *}$ & 0.085 & $-0.221 *$ & 0.100 \\
\hline Log likelihood & \multicolumn{2}{|c|}{-159.3117} & \multicolumn{2}{|c|}{-333.431} & \multicolumn{2}{|c|}{-326.367} & \multicolumn{2}{|l|}{-96.221} & \multicolumn{2}{|c|}{-172.918} & \multicolumn{2}{|c|}{-164.608} \\
\hline & & & & & & & $\begin{array}{l}* * * p<.001 \\
\text { DV }=\text { Depen }\end{array}$ & $\begin{array}{l}* * p<. C \\
\text { ident } \mathrm{V}\end{array}$ & $\begin{array}{l}1 * p<.05 \\
\text { ariable }\end{array}$ & & & \\
\hline
\end{tabular}


Table III. Results from Hypotheses testing

\begin{tabular}{|c|c|c|}
\hline \multicolumn{2}{|r|}{ Hypotheses } & Result \\
\hline $\mathrm{H} 1$ & $\begin{array}{l}\text { In online gambling, emotional arousal is positively } \\
\text { related to addiction issues regardless of impulsive } \\
\text { behavior }\end{array}$ & Supported \\
\hline $\mathrm{H} 2$ & $\begin{array}{l}\text { In online gambling, chasing is positively related to } \\
\text { addiction issues regardless of impulsive behavior }\end{array}$ & Supported \\
\hline H3 & $\begin{array}{l}\text { In online gambling, belief in luck is positively related } \\
\text { to the extent of addiction issues regardless of impulsive } \\
\text { behavior }\end{array}$ & $\begin{array}{l}\text { Partially } \\
\text { supported }\end{array}$ \\
\hline $\mathrm{H} 4$ & $\begin{array}{l}\text { Online gambling attitudes increase the extent of } \\
\text { addiction related issues only for gamblers seeking } \\
\text { smaller and immediate gratification, not for those } \\
\text { seeking larger and delayed rewards }\end{array}$ & Supported \\
\hline H5 & $\begin{array}{l}\text { Factual (illusory) strategies are negatively (positively) } \\
\text { related to addiction issues only for online gamblers } \\
\text { seeking larger and delayed rewards }\end{array}$ & Rejected \\
\hline
\end{tabular}

